\title{
Hubungan antara Anemia dengan Perkembangan Neurologi Anak Usia 12-24 bulan
}

\author{
Nurhayati Masloman, Stefanus Gunawan
}

Latar belakang. Kejadian anemia selama periode kritis perkembangan otak anak dapat mengakibatkan keterlambatan pertumbuhan dan perkembangan anak secara umum. Tujuan. Untuk mengetahui hubungan antara anemia dengan perkembangan neurologi pada anak usia 12-24 bulan.

Metoda. Penelitian analitik dengan desain potong lintang dilakukan di Posyandu Puskesmas Kecamatan Wawonasa mulai bulan September-Oktober 2004. Subjek penelitian adalah anak berusia 12-24 bulan yang memenuhi kriteria inklusi. Penentuan anemia sesuai kriteria WHO (kadar hemoglobin usia 6 bulan -5 tahun $<11 \mathrm{~g} / \mathrm{dl}$ ). Perkembangan anak dinilai menggunakan Bayley Infant Neurodevelopmental Screener (BINS). Hasil pemeriksaan dinyatakan dalam 3 kategori yaitu risiko rendah, risiko sedang dan risiko tinggi. Data dianalisis dengan korelasi Spearman rank.

Hasil. Subjek penelitian 49 anak terdiri dari 31 (63,3\%) laki-laki dan 18 (36,7\%) perempuan; didapat proporsi anak anemia $16(32,7 \%)$. Pada kelompok anemia didapatkan $7(43,8 \%)$ anak kategori risiko tinggi dan $7(43,8 \%)$ risiko sedang. Terdapat hubungan yang lemah antara kadar hemoglobin dengan perkembangan neurologi anak usia 12-24 bulan $\left(r_{s}=0,429 ; p=0,001\right)$.

Kesimpulan. Anak usia 12-24 bulan dengan anemia mempunyai risiko tinggi terhambat dalam perkembangan neurologi.

Kata kunci: anemia, perkembangan neurologi, defisiensi anak

P

erkembangan anak merupakan hasil maturasi organ tubuh, terutama susunan saraf pusat dan perkembangan dipengaruhi oleh lingkungan biofisikopsikososial dan faktor genetik. Dalam perkembangan terdapat berbagai tahapan yang harus

\footnotetext{
Alamat korespondensi:

Dr. Hj. Nurhayati Masloman, Sp.A.

Kepala Subbagian Neurologi, Bagian Ilmu Kesehatan Anak FK Universitas Sam Ratulangi/RSU Prof. R D Kandou, Jalan Raya Tanawangko - Manado 95115. P.O. Box 66.

Telp. 0431 821652. Fax. 0431 859091.Email. ikarsup@telkom.net
}

Dr. Stefanus Gunawan. Peserta PPDS IKA FK UNSRAT, MANADO dilalui seorang anak untuk menuju usia dewasa. Tahapan yang terpenting adalah pada masa 2 tahun pertama kehidupan, karena pada masa ini tumbuh kembang berlangsung dengan pesat dan menentukan masa depan anak. ${ }^{1}$

Faktor gizi memegang peranan yang sangat penting sebagai salah satu penunjang untuk tercapainya hasil tubuh kembang yang optimal, yaitu terwujudnya manusia yang berkualitas. ${ }^{2}$ Anemia gizi adalah keadaan dengan kadar hemoglobin lebih rendah dari normal yang dapat disebabkan akibat defisiensi satu atau lebih nutrien esensial (misalnya zat besi, asam folat, vitamin $A, B_{12}$, dan $C$ serta tembaga). Di negara berkembang, termasuk Indonesia, anemia defisiensi besi (ADB) 
masih merupakan penyebab anemia yang tersering. Berdasarkan Survei kesehatan rumah tangga (SKRT) 1995, prevalensi anemia gizi pada anak berusia $<5$ tahun sebesar $40,5 \% .^{3}$ Secara tradisional pengukuran hemoglobin dapat dipakai untuk menentukan diagnosis anemia gizi. ${ }^{4}$

Telah banyak penelitian melaporkan bahwa ADB mempunyai dampak jangka panjang pada perkembangan psikomotor yang berlangsung lama bahkan mungkin bersifat ireversibel. ${ }^{5-7}$ Bahkan beberapa peneliti melaporkan umumnya anak dengan ADB walaupun sudah diobati dengan zat besi cenderung mempunyai skor perkembangan lebih rendah dibandingkan anak tanpa ADB., ${ }^{5,8}$ Adanya ADB selama periode kritis dalam perkembangan otak dapat menyebabkan kerusakan yang ireversibel sehingga mengakibatkan keterlambatan perkembangan. ${ }^{10}$

Penelitian ini bertujuan untuk mengetahui hubungan antara anemia dengan perkembangan neurologi pada anak berusia 12-24 bulan.

\section{Metoda}

Penelitian ini bersifat analitik dengan menggunakan desain potong lintang dan dilakukan di Posyandu di wilayah kerja Puskesmas Kecamatan Wawonasa mulai bulan September-Oktober 2004.

Subyek penelitian dalam penelitian ini adalah anak berusia 12-24 bulan yang memenuhi kriteria inklusi anak sehat secara fisik, status gizi baik (BB/ $\mathrm{TB} \geq 90 \%$ dan $\leq 110 \%$ sesuai baku NCHS/WHO), berat lahir $\geq 2.500$ gram, status sosial ekonomi orang tua tergolong keluarga miskin (Gakin) berdasarkan kriteria yang ditetapkan oleh Puskesmas, dan terdapat persetujuan tertulis dari orang tua. Kriteria eksklusi yaitu terdapat kelainan kongenital, kelainan perkembangan (palsi serebral, paresis/paralisis) dan riwayat komplikasi prenatal (misalnya asfiksia berat, hiperbilirubinemia, hipoglikemia, sindroma gawat nafas, prematuritas, sepsis). Pengambilan sampel secara consecutive sampling.

Pemeriksaan kadar hemoglobin $(\mathrm{Hb})$ berdasarkan sianmethemoglobin (metoda Sahli). Penentuan anemia pada penelitian ini menggunakan kriteria $\mathrm{WHO}$, yaitu kadar $\mathrm{Hb}$ untuk anak usia 6 bulan -5 tahun adalah kurang dari $11 \mathrm{~g} / \mathrm{dl} .{ }^{4}$ Status perkembangan anak pada penelitian ini dinilai menggunakan Bayley Infant
Neurodevelopmental Screener (BINS), yang mengevaluasi 4 bidang kemampuan yaitu fungsi neurologis dasar, fungsi reseptif, fungsi ekspresif dan fungsi kognitif. Hasil pemeriksaan dinyatakan dalam 3 kategori yaitu risiko rendah, risiko sedang dan risiko tinggi. ${ }^{3}$

Data diolah dengan analisis korelasi Spearman rank menggunakan program komputer SPSS versi 11.0

\section{Hasil}

Selama periode penelitian terdapat 49 anak yang memenuhi kriteria inklusi datang ke Posyandu dan bersedia ikut serta dalam penelitian ini. Subyek terdiri dari $31(63,3 \%)$ anak laki-laki dan 18 (36,7\%) anak perempuan, $16(32,7 \%)$ diantaranya menderita anemia dan $33(67,3 \%)$ kadar hemoglobinnya normal sesuai usianya. Hasil pemeriksaan perkembangan neurologi dengan mempergunakan skor BINS, paling banyak dijumpai anak dengan risiko sedang berjumlah 25 (51\%) anak, sedangkan risiko rendah dan risiko tinggi jumlahnya sama, yaitu masing-masing 12 (24,5\%) anak. Data karakteristik sampel selengkapnya terdapat pada Tabel 1.

Pada kelompok anak dengan anemia didapatkan $7(43,8 \%)$ anak dengan skor BINS termasuk kategori risiko tinggi dan 7 (43,8\%) anak risiko sedang. Pada Tabel 2 terlihat pula anak yang memiliki $\mathrm{Hb}<10 \mathrm{~g} / \mathrm{dl}$ semuanya berisiko tinggi mengalami hambatan perkembangan neurologi.

Nilai perkembangan neurologi anak diukur dengan skor BINS yang dikategorikan dalam 3 kategori perkembangan, yaitu risiko rendah, risiko sedang dan risiko tinggi (data ordinal); sedangkan kadar $\mathrm{Hb}$ diukur dengan skala interval maka hubungan antara kedua variabel tersebut dianalisis dengan analisis korelasi Spearman rank (rho). Analisis ini menghasilkan nilai koefisien korelasi $\left(\mathrm{r}_{\mathrm{s}}\right)$ $=0,429$ dengan $\mathrm{p}=0,001$. Nilai $\mathrm{p}<0,001$ berarti hasil tersebut bukan akibat faktor kebetulan, yang perlu dinilai adalah besarnya koefisien $r_{s}=0,429$ ini berarti korelasi sangat lemah (biasanya $r<0,5$ dikategorikan lemah). Dengan demikian terdapat hubungan yang lemah antara kadar $\mathrm{Hb}$ dengan perkembangan neurologi anak usia 12-24 bulan, yaitu anak dengan kadar $\mathrm{Hb}$ rendah mempunyai risiko tinggi terhambat dalam perkembangan neurologi. 
Sari Pediatri, Vol. 7, No. 4, Maret 2006

Tabel 1. Karakteristik sampel menurut kelompok umur $(\mathrm{n}=49)$

\begin{tabular}{ccccc}
\hline \multirow{2}{*}{ Variabel } & \multicolumn{3}{c}{ Umur (bulan) } & Total \\
\cline { 2 - 5 } & $12-15(\%)$ & $16-20(\%)$ & $21-24(\%)$ \\
\hline Jenis Kelamin & & & & \\
· Laki-laki & $9(29)$ & $10(32,3)$ & $12(38,7)$ & $31(100)$ \\
. Perempuan & $6(33,3)$ & $4(22,2)$ & $8(44,5)$ & $18(100)$ \\
Kadar Hb (g/dl) & & & & \\
· Anemia $(<11)$ & $5(31,3 \%)$ & $4(25)$ & $7(43,7)$ & $16(100)$ \\
- Normal $(\geq 11)$ & $10(30,3 \%)$ & $10(30,3)$ & $13(39,4)$ & $33(100)$ \\
Kategori BINS & & & & \\
- Risiko rendah & $2(16,7)$ & $2(16,7)$ & $8(66,7)$ & $12(100)$ \\
- Risiko sedang & $9(36)$ & $9(36)$ & $7(28)$ & $25(100)$ \\
- Risiko tinggi & $4(33,3)$ & $3(25)$ & $5(41,7)$ & $12(100)$ \\
\hline
\end{tabular}

${ }^{*}$ BINS = Bayley Infant Neurodevelopmental Screener

Tabel 2. Sebaran anak menurut kadar $\mathrm{Hb}$ dan perkembangan neurologi $(\mathrm{n}=49)$

\begin{tabular}{ccccc}
\hline Kadar Hemoglobin & \multicolumn{3}{c}{ Kategori BINS } & Total \\
\cline { 2 - 5 }$(\mathrm{g} / \mathrm{dl})$ & Risiko rendah & Risiko sedang & Risiko tinggi \\
\hline $8,0-<8,9$ & 0 & 0 & 1 & 1 \\
$9,0-<9,9$ & 0 & 0 & 5 & 5 \\
$10,0-<10,9$ & 2 & 7 & 1 & 10 \\
$11,0-<11,9$ & 4 & 10 & 4 & 18 \\
$12,0-<12,9$ & 6 & 6 & 1 & 13 \\
$13,0-<13,9$ & 0 & 2 & 0 & 2 \\
\hline Total & 12 & 25 & 12 & 49 \\
\hline
\end{tabular}

\section{Pembahasan}

Dalam penelitian ini didapatkan anemia pada anak berusia 12-24 bulan (kadar $\mathrm{Hb}<11 \mathrm{~g} / \mathrm{dl}$ ) sebanyak $32,7 \%$. Angka ini lebih rendah dibandingkan dengan data SKRT tahun 1995 (anemia pada usia $<5$ tahun 40,5\%) hal ini karena sampel yang dipilih hanya anak dengan status gizi baik. Anemia dapat terjadi pada anak-anak dengan gizi baik bila asupan makanan anakanak tersebut kurang mengandung zat besi atau terdapat zat-zat yang menghambat absorbsi besi. ${ }^{12}$ Pada penelitian ini tidak diteliti lebih lanjut mengenai komposisi makanan anak-anak tersebut.

Skor BINS risiko tinggi berarti anak menderita keterlambatan perkembangan, pada subyek penelitian memperlihatkan hasil sebesar $24,5 \%$. Di Amerika Serikat dilaporkan prevalensi anak dengan gangguan perkembangan sebesar $12-16 \% .{ }^{13} \mathrm{Di}$ negara-negara berkembang seperti Indonesia, faktor lingkungan berperan besar terhadap risiko penyimpangan proses tumbuh kembang yang umumnya dilatarbelakangi oleh kemiskinan dan ketidaktahuan masyarakat terhadap proses tumbuh kembang. Keadaan tersebut sering dijumpai di daerah dengan karakteristik penduduk padat, pendidikan dan pendapatan rendah. ${ }^{12,14}$

Dari 12 anak dengan skor BINS risiko tinggi terdapat $7(58,3 \%)$ anak dengan anemia. Di negara berkembang, prevalensi anemia masih tinggi dengan penyebab tersering adalah ADB., ${ }^{3,4}$ Defisiensi besi selama periode kritis perkembangan otak diduga dapat menyebabkan kerusakan yang ireversibel sehingga mengakibatkan keterlambatan perkembangan. ${ }^{13}$ Lozoff, dkk ${ }^{5-7}$ telah melakukan penelitian yang mendalam tentang hubungan defisiensi besi dengan perkembangan neurologi anak. Pada penelitiannya yang pertama terhadap 191 anak di Costa Rica berusia 12-23 bulan dengan menggunakan BINS, dilaporkan anak yang menderita defisiensi besi mempunyai skor motoris dan mental yang lebih rendah. ${ }^{5}$ Selanjutnya pada usia 5 tahun kelompok anak yang sama diperiksa ulang dan dilaporkan anak-anak dengan riwayat $\mathrm{ADB}$ 
pada masa bayinya mempunyai skor motoris dan mental yang lebih rendah dibandingkan anak normal. ${ }^{6}$ Demikian pula pada usia 11-14 tahun, kelompok yang sama diperiksa kembali dan dilaporkan bahwa pada anak-anak dengan riwayat $\mathrm{ADB}$ selama masa bayi sekali lagi memperlihatkan defisit skor IQ, motorik dan verbal serta mengalami problem spesifik dalam hal menulis dan mata pelajaran matematika. ${ }^{7}$ Sherriff, $\mathrm{dkk}^{15}$ melaporkan gangguan lokomotor pada usia 18 bulan pada anak dengan riwayat ADB masa bayinya.

Derajat beratnya defisiensi besi yang dapat menyebabkan keterlambatan perkembangan masih kontroversial. Lozoff, $\mathrm{dkk}^{5}$ memperlihatkan hanya anak dengan $\mathrm{ADB}$ yang menderita keterlambatan perkembangan, sedangkan Oski, dkk ${ }^{16}$ melaporkan keterlambatan perkembangan pada anak dengan defisiensi besi non-anemis. Besi sangat dibutuhkan untuk metabolisme susunan saraf pusat karena peranannya dalam sintesis neurotransmiter, pembentukan mielin dan pertumbuhan otak. Sistim neurotransmiter susunan saraf pusat sangat sensitif terhadap perubahan status besi. Bila kandungan besi total dalam otak berkurang $15 \%$ di bawah normal, dapat mengakibatkan gangguan sistim neurotransmiter tersebut. Defisiensi besi selama periode kritis perkembangan otak diduga menyebabkan kerusakan yang ireversibel sehingga mengakibatkan terjadinya keterlambatan perkembangan. ${ }^{10}$ Hasil penelitian ini memperlihatkan nilai koefisien korelasi Spearman rank $\left(r_{s}\right)=0,429$ dengan $\mathrm{p}=0,001$; sehingga dapat disimpulkan terdapat hubungan yang lemah antara anemia dengan perkembangan neurologi anak usia 1224 bulan, yaitu anak dengan kadar $\mathrm{Hb}$ yang rendah mempunyai risiko tinggi mengalami hambatan perkembangan neurologi.

\section{Daftar Pustaka}

1. Soetjiningsih. Perkembangan anak dan permasalahannya. Dalam: Narendra MB, Sularyo H, Ranuh IGN, penyunting. Buku ajar tumbuh kembang anak dan remaja. Edisi 1. Jakarta: Sagung Seto; 2002. h. 86-94.

2. Agusman IS. Deteksi dan intervensi dini penyimpangan tumbuh kembang akibat defisiensi zat gizi. Dalam: Sularyo TS, Musa DA, Gunardi H, penyunting. Deteksi dan intervensi dini penyimpangan tumbuh kembang anak dalam upaya optimalisasi kualitas sumber daya manusia. Naskah lengkap PKB IKA XXXVII. Jakarta:
BP FKUI; 1996. h. 147-61.

3. Permono B, Ugrasena IDG. Anemia defisiensi besi (patofisiologi dan penatalaksanaannya). Naskah lengkap continuing education IKA XXXII. Surabaya, 26-27 Oktober 2002.

4. Schrinshaw NS. Frequency, cause and significance of iron deficiency for the children of central asia. Dalam: WHO International Child Health: A digest of current information 1998; IX: 47-60

5. Lozoff B, Brittenham GM, Wolf AW. Iron deficiency anemia and iron therapy effect on infant developmental test performance. Pediatrics 1987; 79: 981-95.

6. Lozoff B, Jimenez E, Wolf AW. Long-term developmental outcome of infants with iron deficency. N Engl J Med 1991; 325: 687-94.

7. Lozoff B, Jimenez E, Hagen J, Mollen E, Wolf AW. Poorer behavioral and developmental outcome more than 10 years after treatment for iron deficiency in infancy. Pediatrics 2000;105(4). Didapat dari: http:// www.pediatrics.org/cgi/content/full/105/4/e51

8. Grantham-McGregor S, Ani A. Review of studies on the effect of iron deficiency on cognitive development in children. J Nutr. 2001; 649S-668S.

9. Lozoff B, Klein NK, Nelson EC, McClish DK, Manuel $\mathrm{M}$, Chacon ME. Behavior of infants with iron-deficiency anemia. Child Devl. 1998; 69: 24-36.

10. Beard JL. Iron biology in immune function, muscle metabolism and neuronal functioning. J Nutr 2001;131: 568s-80s.

11. Pusponegoro HD. Bayley Infant Neurodevelopmental Screener: Skrining anak 3-24 bulan. Disampaikan pada Nutricia Scientific Workshop 2003: Neurodevelopmental asessement in young children, the importance of subtle signs and symtomps of developmental problems. Manado, 1-2 September 2003.

12. Harahap H, Jahari1 AB, Husaini MA, Saco-Pollitt C, Pollitt E. Effects of an energy and micronutrient supplement on iron deficiency anemia, physical activity and motor and mental development in undernourished children in Indonesia. Eur J Clin Nutr 2000; 54 Suppl 2: S114-9.

13. American Academy of Pediatrics, Committee on children with disabilities. Development surveillance and screeening of infants and young children (REOO62): policy statement. Pediatrics 2001; 108:192-6.

14. Rivera JA, Sotres-Alvarez D, Habicht J, Shamah T, Villalpando S. Impact of the Mexican program for education, health, and nutrition (Progresa) on rates of growth and anemia in infants and young children 
a randomized effectiveness study. JAMA 2004; 291:2563-70.

15. Sherriff A, Emond A, Bell JC, dkk. Should infants be screened for anaemia? A prospective study investigating the relation between haemoglobin at 8,12 , and 18 months and development at 18 months. Arch Dis Child. 2001; 84:480-5.

16. Oski FA, Honig AS, Helu B, Howanitz P. Effect of iron therapy on behavior performance in non-anemic iron deficient infants. Pediatrics 1983; 71:877-80. 